\title{
Oculocutaneous albinism among schoolchildren in Harare, Zimbabwe
}

\author{
Fewstar Kagore, Patricia M Lund
}

\begin{abstract}
The term oculocutaneous albinism (OCA) covers a range of autosomal recessive genetic conditions involving hypopigmentation of the skin, hair, and eyes. In southern African black ethnic groups the tyrosinase positive form, OCA2, is predominant, with few cases of tyrosinase negative OCA1. The prevalence of OCA2 in schoolchildren in Harare, the capital city of Zimbabwe, was found to be 1 in 2833 . The gene frequency for OCA2 was $0 \cdot 0188$, with a carrier frequency of 1 in 27. Most of the pupils with albinism belonged to the majority Shona ethnic group. As consanguineous marriages are discouraged in the Shona culture this high rate is likely to be a result of genetic drift in a relatively small population showing limited mobility. OCA pupils were found in more than a third of the secondary schools in Harare, emphasising the importance of distributing information on albinism and its management widely throughout the school system.
\end{abstract}

( $\mathcal{F}$ Med Genet 1995;32:859-861)

Oculocutaneous albinism (OCA) covers a heterogeneous range of genetic conditions showing an autosomal recessive pattern of inheritance where the production of melanin pigment in the skin, eye, and hair follicle is reduced or completely absent. In tyrosinase negative OCA (also referred to as OCA1) tyrosinase, the key enzyme in the biosynthetic pathway leading to melanin production is deficient, either completely absent or showing reduced activity. As a result little or no pigment is produced. In the tyrosinase positive form of OCA (OCA2) the tyrosinase gene and protein are normal, yet little pigment results. ${ }^{1-3}$ The gene for this type of albinism, located on chromosome $15,{ }^{4}$ has recently been cloned. ${ }^{5}$ It encodes the $P$ polypeptide, a transmembrane protein with structural homology to known transporters of small organic molecules, ${ }^{6}$ but its specific function is unknown. An interstitial deletion of the P gene has been described in unrelated African Americans with OCA2 as well as in two subjects from Cameroon and Zaire. ${ }^{7}$ The African origin of this $2.7 \mathrm{~kb}$ deletion mutation was confirmed when the same allele was found in 114/146 OCA2 chromosomes of 74 unrelated southern African Negroids with OCA2. ${ }^{8}$ The same deletion allele has recently been identified in one Shona family in Zimbabwe. ${ }^{9}$

The clinical features of OCA 2 in a population where the normal pigmentation of the skin, hair, and eyes is black or dark brown are clearly distinguishable. The hair of affected people is sandy coloured, the irides are blue or light brown, and the skin is chalky white, often with pigmented naevi or lentigines. Visual acuity is reduced and nystagmus and photophobia are present. There is some accumulation of yellowred pheomelanin in the hair and irides with age, although the brown-black eumelanin is almost completely absent. ${ }^{4}$ Their skin burns but does not tan. Hypopigmentation of the skin predisposes subjects with albinism to skin cancer which results in significant mortality among affected people in Africa, particularly among those living in the tropics. ${ }^{10-12}$ In southern Africa OCA1 is rare in Negroid populations. ${ }^{13}$

Although albinism is found throughout the world the prevalence in different population groups varies widely. In the USA the prevalence of OCA2 among whites is about 1 in 36000 whereas in certain isolated groups, such as the Hopi Indians in Arizona, it is exceptionally high, 1 in 277. ${ }^{1}$ In Soweto, South Africa, the prevalence of OCA among the black population was estimated at 1 in 3900 , being more common in the Sotho-Tswana than in the Nguni ethnic groups in this city. ${ }^{14}$ The estimate for Dar-es-Salaam, Tanzania, 1 in 1429, indicates an even higher rate. ${ }^{12}$ The frequency of albinism was 1 in 1634 among schoolchildren in Swaziland. ${ }^{15}$ OCA is thus a relatively common genetic condition throughout southern and central Africa.

No data on albinism were available for Zimbabwe, a country situated to the north of South Africa. This paper presents data from a survey of all secondary schools in Harare, the capital city of Zimbabwe, where the major ethnic group is the Shona. The second largest indigenous ethnic group in Zimbabwe is the Ndebele, related to the Nguni of South Africa. They are found mainly in the south and south west of the country, although this group is also represented in the capital. Zimbabwe has a reliable postal system and an excellent education system, making it an ideal country in which to collect accurate population data in the school going age group.

\section{Methods}

A postal survey of all secondary schools falling within the Harare regional office of the Ministry of Education and Culture in Zimbabwe was conducted in one school year (1994). Permission for the survey was obtained from the Ministry of Education and Culture and from the regional education office. The latter pro- 
vided a list of the names and addresses of the 69 secondary schools within their area. A questionnaire sent to heads of schools requested the following information: the number of male and female pupils in the school, the age range of pupils, the different ethnic groups represented at the school, the number of pupils with albinism in the school, and the age, form, and ethnic origin of these pupils. Schools with pupils with this condition were asked if they made any special provisions to cater for them. A letter to the head was included in the mailing, giving the Shona and Ndebele names for albinism (supe and n'kau respectively) and the following description of OCA.

"Albinos show a lack of pigmentation of the skin, hair and eyes. They tend to have pale skin, often with darker patches or freckles on parts of the body exposed to the sun, and light brown or pale blue eyes. There are often visual problems associated with albinism, including squinting and rapid eye movements."

A second mailing was sent after three months; schools which did not respond to either mailing were visited and the data collected in person. Personal visits were made to confirm most of the cases of albinism with the OCA phenotype established by clinical observation. Eight affected pupils were interviewed in their own homes. Details of family members, whether the parents were related, and of the management of their condition were obtained in these interviews. Leaflets giving detailed information about albinism, its management, and the pattern of inheritance were given to each participant and posted to schools having pupils with albinism.

\section{Results}

Complete ascertainment of the study group was achieved with $78.3 \%$ of the schools responding by mailed questionnaires and the remainder through personal visits. The total number of pupils enrolled in secondary schools in Harare in 1994 was 87817 (table). The age of pupils was 12 to 22 years. The majority were Shona, although pupils from other ethnic groups were present, including Ndebele, as well as those of Asian and European extraction and those from neighbouring countries. It proved impossible to collect data on the number of pupils belonging to each ethnic group as schools did not keep such records.

A total of 24 of the 69 schools (34.8\%) had at least one pupil with albinism; 33 affected pupils were identified in the total sample size

Prevalence of OCA among secondary schoolchildren in Harare, Zimbabwe

\begin{tabular}{lccc}
\hline & Males & Females & \multicolumn{1}{l}{ Total } \\
\hline Normally pigmented & 45935 & 41849 & 87784 \\
OCA & 17 & $16^{*}$ & 33 \\
Total & 45952 & 41865 & 87817 \\
OCA prevalence & $1 / 2703$ & $1 / 2617$ & $1 / 2661$ \\
OCA2 prevalence & $1 / 2703$ & $1 / 2990$ & $1 / 2833$ \\
\hline
\end{tabular}

* The OCA status of the two white females with albinism was not established. The remainder all had tyrosinase positive albinism (OCA2). of 87817 pupils (table) resulting in a prevalence of 1 in 2661 . The sex ratio of subjects with OCA was 1.06 which is not significantly different from the expected ratio of 1 . The age range of these pupils was 13 to 20 years, with a mean of 15.3 years. There were two white pupils with albinism, two of mixed African ancestry, one of African origin from a neighbouring country, two Ndebele, and 26 Shona. When the two white pupils with OCA were excluded from the data because the specific type of their OCA could not be established, the prevalence was 1 in 2883. Assuming Hardy-Weinberg equilibrium, the frequency of the tyrosinase positive (OCA2) allele in this population was calculated to be $0 \cdot 0188$, with a heterozygote frequency of 1 in $27 \cdot 1$. There was no evidence of consanguinity among the parents of children with OCA. Four families had more than one affected child. In one large family of 11 members, four males had albinism.

The majority $(66 \cdot 7 \%)$ of the schools made special provisions for their pupils with albinism, including allowing them to sit close to the chalkboard, limiting outside sports and gardening activities, and allowing them to wear hats to protect their head and neck. The pupils with albinism were noted to hold reading material close to their eyes, and many had developed a head tilt. None wore spectacles. All were aware of the need to protect their skin from the sun and wore hats. Only one used a sunscreen regularly. None of the pupils with albinism was aware that albinism is an inherited condition. They either said they did not know why they had albinism, or thought it was the result of shortage of some vital food during the mother's pregnancy, or that it was “just God's creation".

\section{Discussion}

The prevalence of albinism among children at secondary schools in Harare was found to be 1 in 2661. This is close to the value of 1 in 2792 found in primary schools (Chipoyera, Keogh, and Lund, unpublished data), suggesting that albinos in the capital city do not suffer any educational disadvantage compared with their normally pigmented peers. The prevalence in Harare schools is higher than that reported for a South African study of Soweto, where the prevalence of OCA among the mixture of ethnic groups found in this city was 1 in $3900 .^{14}$ The prevalence of OCA among secondary schoolchildren in Harare is, however, lower than that found for schoolchildren in Swaziland, 1 in $1634 .{ }^{15}$ These data confirm the observation that OCA is a relatively common genetic condition among the different ethnic groups of African origin throughout subSaharan Africa.

Most of the pupils with albinism identified in this study belonged to the majority Shona ethnic group. There was no evidence of consanguineous marriages in the families interviewed. In the Shona culture, marriages between close relatives are discouraged. The Shona are divided into groups identified by different totems, with a child inheriting the 
totem of the father. Marriages between people within the same totem are usually taboo. ${ }^{16}$ In the Soweto study, the prevalence of OCA among the Southern Sotho and Tswana groups ( 1 in 2041 and 1 in 3481), both of which encourage consanguineous unions, was higher than among the Zulu and other Nguni groups where marriages between relatives is taboo. ${ }^{14}$ The prevalence reported here is closer to that for the Sotho and Tswana than the Nguni groups, although the Shona marriage customs discourage consanguineous marriages. This casts some doubt on the relevance of consanguinity as a major cause of the difference observed. The Shona arrived in Zimbabwe around $300 \mathrm{AD}$ and represent a relatively small population that has shown limited mobility. Genetic drift, and possibly heterozygote advantage, may therefore account for the high prevalence of OCA2 among the Shona.

Although none of the pupils interviewed was aware of the genetic basis of albinism, they all managed their condition by wearing protective clothing and limiting their exposure to the sun. This is especially important as Harare is located in the tropics and has a relatively high ultraviolet radiation level, thus increasing the risk of skin lesions and cancer in those with OCA. Financial constraints prohibited the regular use of sunscreen preparations in most cases although these are available at chemists. It is noteworthy that these pupils with albinism were all being educated in the normal schooling system and were coping despite their poor eyesight and absence of spectacles.

The lack of knowledge about the cause of albinism indicates a clear need for genetic and medical information to be made available to both teachers and pupils. Regional efforts to coordinate genetic services within southern Africa should be encouraged as these are likely to be too costly to provide for most individual countries within the region.

This research was funded by the University of Zimbabwe. Part of the work was presented by one of the authors (FK) towards a BSc (Hons) degree. The generous help and encouragement given by heads of schools and by the affected pupils themselves given by heads of schools and by the affected pupils themselves
is gratefully acknowledged. The authors wish to thank Richard A King for his helpful comments on the manuscript.

1 Witkop CJ, Quevedo WC, Fitzpatrick TB, King RA. Albinsim. In: Scriver CR, Beaudet AL, Sly WS, Valle D, eds. The metabolic basis of inherited disease. 6th ed. New York: McGraw-Hill, 1989:2905-47.

2 King RA, Summers CG. Albinism. Dermatol Clin 1988;6: 217-28.

3 Oetting WS, King RA. Molecular basis of oculocutaneous albinism. $\mathcal{F}$ Invest Dermatol 1994;103:131-6S.

4 Ramsay M, Colman M, Stevens G, et al. The tyrosinasepositive oculocutaneous albinism locus maps to chrompositive oculocutaneous albinism locus maps to chrom-
osome 15q11.2q12. Am $\Im$ Hum Genet 1992;51:879-84.

5 Rinchik EM, Bultman SJ, Horsthemke B, et al. A gene for the mouse pink-eyed dilution locus and for human type
the the mouse pink-eyed dilution locus and for human

6 Lee S, Nicholls RD, Bundey S, Laxova R, Musarella M, Spritz RA. Mutations of the $P$ gene in oculocutaneous albinism, ocular albinism, and Prader-Willi syndrome plus albinism. N Engl F Med 1994;330:529-34.

7 Durham-Pierre D, Gardner JM, Nakatsu Y, et al. African origin of an intragenic deletion of the human $\mathrm{P}$ gene in tyrosinase positive oculocutaneous albinism. Nature Genet 1994;7:176-9.

8 Stevens G, van Beukering J, Jenkins T, Ramsay $M$. An intragenic deletion of the $\mathrm{P}$ gene is the common mutation causing tyrosinase-positive oculocutaneous albinism 1995;56:586-91.

9 Durham-Pierre D, King RA, Aquaron R, et al. A $2.7 \mathrm{~kb}$ deletion allele of the $P$ gene associated with OCA2 is common among American Africans and Africans. (In preparation.)

10 Kromberg JGR, Castle D, Zwane EM, Jenkins T. Albinsim and skin cancer in southern Africa. Clin Genet 1989;36: 43-52.

11 Okoro AN. Albinism in Nigeria. Br $\mathcal{F}$ Dermatol 1975;92: 485-92.

12 Luande J, Henschke CI, Mohammed N. The Tanzanian human albino skin. Cancer 1985;55:1823-8.

13 Roberts DF, Kromberg JGR, Jenkins T. Differentiation of heterozygotes in recessive albinism. $\mathcal{F}$ Med Genet 1986;23: 323-7.

14 Kromberg JGR, Jenkins T. Prevalence of albinism in the South African negro. $S$ Afr Med $₹$ 1982;61:383-6.

15 Ewusie JY. Characterization of the genetic profile of Swaziland, the ABO blood groups and albinism. Swazi $\mathcal{F} \mathrm{Sci}$ Technol 1988;9:45-55.

16 Beach DN. The Shona and Zimbabwe 900-1850. Zimbabwe: Mambo Press, 1990. 